\title{
PCB slot based transformers to avoid common-mode resonances in connected arrays of dipoles
}

Citation for published version (APA):

Cavallo, D., Neto, A., \& Gerini, G. (2010). PCB slot based transformers to avoid common-mode resonances in connected arrays of dipoles. IEEE Transactions on Antennas and Propagation, 58(8), 2767-2771.

https://doi.org/10.1109/TAP.2010.2050430

DOI:

10.1109/TAP.2010.2050430

Document status and date:

Published: 01/01/2010

Document Version:

Publisher's PDF, also known as Version of Record (includes final page, issue and volume numbers)

Please check the document version of this publication:

- A submitted manuscript is the version of the article upon submission and before peer-review. There can be important differences between the submitted version and the official published version of record. People interested in the research are advised to contact the author for the final version of the publication, or visit the $\mathrm{DOI}$ to the publisher's website.

- The final author version and the galley proof are versions of the publication after peer review.

- The final published version features the final layout of the paper including the volume, issue and page numbers.

Link to publication

\section{General rights}

Copyright and moral rights for the publications made accessible in the public portal are retained by the authors and/or other copyright owners and it is a condition of accessing publications that users recognise and abide by the legal requirements associated with these rights.

- Users may download and print one copy of any publication from the public portal for the purpose of private study or research.

- You may not further distribute the material or use it for any profit-making activity or commercial gain

- You may freely distribute the URL identifying the publication in the public portal.

If the publication is distributed under the terms of Article 25fa of the Dutch Copyright Act, indicated by the "Taverne" license above, please follow below link for the End User Agreement:

www.tue.nl/taverne

Take down policy

If you believe that this document breaches copyright please contact us at:

openaccess@tue.nl

providing details and we will investigate your claim. 


\section{PCB Slot Based Transformers to Avoid Common-Mode Resonances in Connected Arrays of Dipoles}

\author{
D. Cavallo, A. Neto, and G. Gerini
}

\begin{abstract}
The scanning performances of connected arrays are degraded by the excitation of common-mode resonances that are compatible with balanced feeding lines. Here, a strategy to avoid these resonances is outlined. The strategy involves feeding the dipoles via printed circuit board (PCB) based transformers and significantly reducing the feeding periods in the direction of the dipoles. The number of transmit/receive $(T / R)$ modules does not have to be increased as a consequence of the increased sampling of the dipoles. Full wave simulations that validate the procedure are presented.
\end{abstract}

Index Terms-Microstrip components, phased arrays, slot fed antennnas, ultrawideband antennas.

\section{INTRODUCTION}

The realization of wideband, wide-scanning angle, phased arrays with good polarization performance has been recently receiving increasing attention. Such characteristics are required in a number of applications, such as multi-function defense and security radars in X-band and lower, communication applications in Ku-band, earth based deep space investigation (e.g., square kilometer array, [1], [2]), and satellite based sub-mm wave instruments (e.g., SPICA, [4]).

Although tapered slot antennas have broad bandwidth, they are known to produce high cross-polarized components in the radiation patterns, especially in the planes at $45^{\circ}$ to the planes containing the slots, [5]. Therefore, a relatively complicated antenna arrangement is necessary to reduce these levels in dual-polarization applications. On the other hand, conventional phased arrays based on printed radiating elements can achieve only moderate bandwidths $(\sim 25 \%)$, [6]-[8]. There is a recent trend aiming at reducing cross-polarization by making arrays of long dipoles or slots periodically fed, with all the radiating parts lying in the array plane according to Wheeler's continuous current sheet ([9]): these arrays are indicated as connected arrays of slot or dipoles. Connected arrays offer wide bandwidth, as shown in [10][11], while maintaining low cross-polarization (X-pol) levels.

Scanning performance of planar connected arrays of dipoles and slots were compared in [12], where an investigation based on the Green's function of the two structures was presented. The analysis showed that dipole arrays can achieve broader bandwidth than slots for wide scanning (up to $45^{\circ}$ ). A conformal versions of connected array has been recently proposed and investigated, [3]. Despite the potentials, the practical implementation of the feeding network in a connected array of dipoles is a difficult problem. Balanced transmission lines should be used to feed the elements. However these lines can support both differential and common-mode propagation. This

Manuscript received June 23, 2009; revised November 27, 2009, February 17, 2010; accepted February 17, 2010. Date of publication May 18, 2010; date of current version August 05, 2010.

D. Cavallo and G. Gerini are with TNO, Defense, Security and Safety, 2597 AK The Hague, Netherlands and also with the Faculty of Electrical Engineering, Eindhoven University of Technology, 5612 AZ Eindhoven, Netherlands (e-mail: daniele.cavallo@tno.nl; giampiero.gerini@tno.nl).

A. Neto is with the Telecommunication Department, Delft University of Technology, Mekelweg 4, 2628 CD Delft, Netherlands (e-mail: A.Neto@tudelft.nl).

Color versions of one or more of the figures in this communication are available online at http://ieeexplore.ieee.org.

Digital Object Identifier 10.1109/TAP.2010.2050430

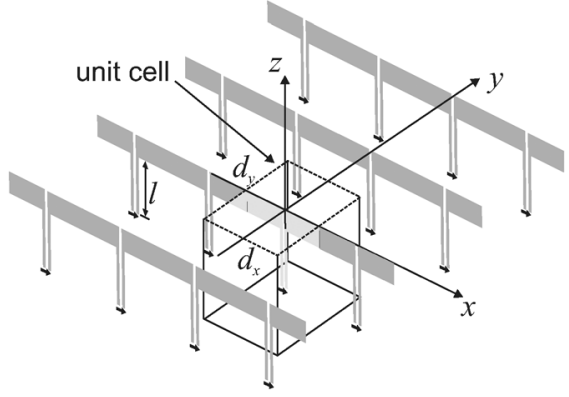

Fig. 1. Geometry of a two dimensional array of dipoles fed by CPS lines. The periodicity along $x$ and $y$ is $d_{x}$ and $d_{y}$, respectively. The length of the vertical feeding lines is $l$.

latter is undesired, since it can give rise to strong resonances that ruin the array performance. An analysis of the effects of these resonances on the efficiency of a connected array was presented in [13]. The same type of resonances were also observed and investigated for arrays of differentially-fed tapered slot antennas in [14]. When the array periodicity is in the order of half wavelength, standard baluns or common-mode rejection circuits are not effective as will be shown in the following.

A low cost, printed circuit board (PCB) based solution to the common-mode resonances, without resorting to active components or MMIC technology, is proposed in this communication. It is based on reducing the lengths of the resonating lines in order to shift the common-mode resonances to higher frequencies, so outside the wide operational bandwidths of the arrays. This effect is achieved by applying a denser sampling of the array, but still maintaining the same numbers of $\mathrm{T} / \mathrm{R}$ modules by means of power dividers. A wideband transition between co-planar strip (CPS) lines has been designed, based on microstrip-to-slot aperture coupling, [15], to further reduce the length of continuous current paths. The The same transition can be used as a balun, when coupling a CPS line to a microstrip (MS).

\section{RESONANCES TYPICAL OF CONNECTED ARRAYS}

Let us consider the simplified case of an infinite two-dimensional array of dipoles with periodicity $d_{x}$ and $d_{y}$, as shown in Fig. 1. Backing reflectors diminish the intrinsic bandwidth of the dipoles (theoretically infinite). For sake of generality, the array without backing reflector has been studied in order to highlight only the frequency dependence introduced by the feeding network. The array elements are fed by CPS lines, whose length is equal to $l$.

Three types of resonant effects may occur in these, otherwise broadband, connected arrays:

1) grating lobes;

2) phase matching between Floquet waves (FW) and guided waves;

3) common-mode resonances.

The first type resonance is associated with the appearance into the visible region of an higher order FW and is typical of all arrays, connected and not connected. The second type resonance only occurs in connected arrays, since in an infinitely extended dipole structure, guided waves can propagate unattenuated along the longitudinal direction. As described in Section III.B of [12], when the dipole is assumed to be in free space, these waves are represented in the spectral Green's function (GF) as a couple of poles in $k_{x}= \pm k_{0}$. The first two types of resonance are not dependent on the feeding lines, thus they can be taken into account in an ideal model that does not include transmission lines. 


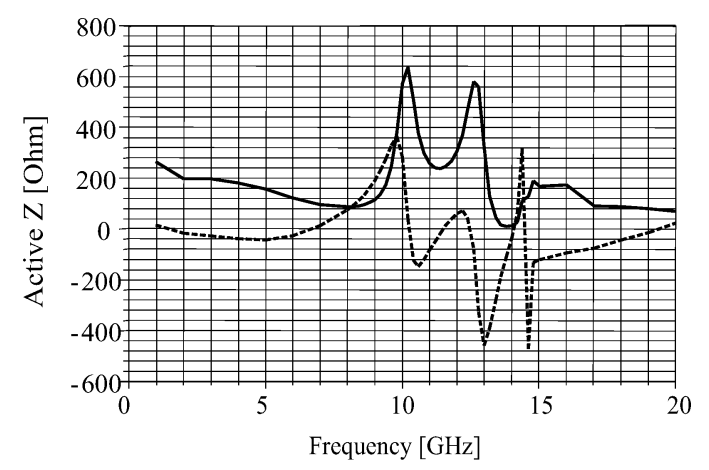

Fig. 2. Real (-) and imaginary (- - ) part of the active input impedance of an elementary cell in infinite array environment, when the array is scanning towards $\theta=45^{\circ}$ and $\phi=45^{\circ}$. The periods are $d_{x}=d_{y}=15 \mathrm{~mm}$ and the length on the vertical lines is $l=7.5 \mathrm{~mm}$.
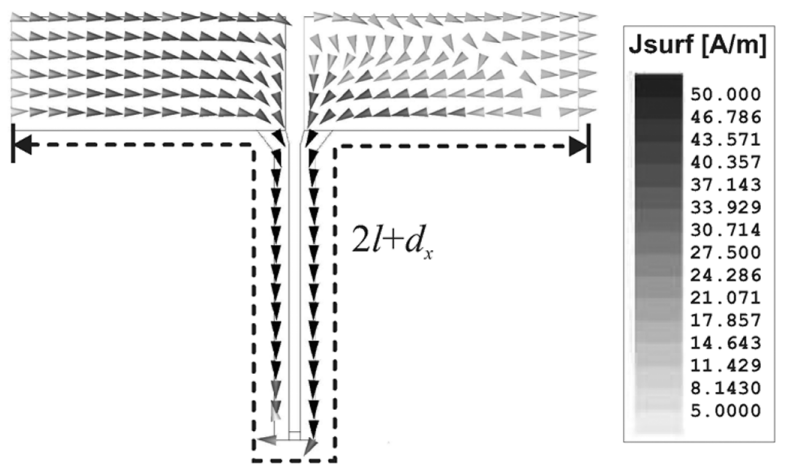

Fig. 3. Vector surface current distribution on an elementary dipole in infinite array environment at $10 \mathrm{GHz}$. the array is scanning towards $\theta=45^{\circ}$ and $\phi=$ $45^{\circ}$. The periods are $d_{x}=d_{y}=15 \mathrm{~mm}$ and the length on the vertical lines is $l=7.5 \mathrm{~mm}$. Common-mode propagation is visible in the vertical feeding lines.

\section{A. Common-Mode Resonances}

If differential lines are included in the model, their length is critical since they may induce other resonances due to common-mode propagation. The shorter the feeding lines, the higher the associated resonant frequency. However, typically connected arrays involve the presence of a backing reflector. Accordingly, the transmission line lengths are in the order of a quarter of the free space wavelength, in order to reach the ground-plane level, where loads or source circuits are located. As an example, in the most standard design situation in which the periodicity of the array is about half wavelength, and the vertical lines are a quarter wavelength, two neighboring feeding lines together with the electrical connection via the dipole constitute a wavelength continuous electric path $\left(d_{x}+2 l=\lambda\right)$ that gives rise to a strongly cross-polarizing standing wave.

The active input impedance for an array periodicity of $d_{x}=d_{y}=$ $15 \mathrm{~mm}$, and assuming $l=7.5 \mathrm{~mm}$, is shown in Fig. 2. In addition to the grating lobe and the guided pole resonances (at about 14.5 and $13.5 \mathrm{GHz}$, respectively), a peak of the impedance appears at $10 \mathrm{GHz}$. By observing the vector current distribution, the resonance can be recognized as associated with common-mode propagation in the CPS lines (Fig. 3). According to the third definition of cross polarization by Ludwig, [16], common-mode currents along $z$ radiate cross-polarized fields when scanning on the diagonal plane $\left(\phi=45^{\circ}\right.$. In Fig. 4 , the ratio between co-polarized and cross-polarized fields rapidly increases in proximity of the resonance at $10 \mathrm{GHz}$. Therefore, to ensure low $\mathrm{X}$-pol level, the length of the path $2 l+d_{x}$ should be significantly shorter than a wavelength, so that the common-mode resonances

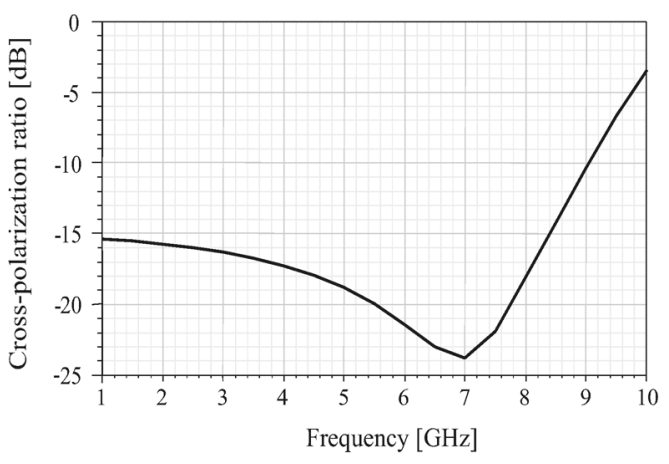

Fig. 4. Cross-polarization level as a function of frequency when scanning towards $\theta=45^{\circ}$ and $\phi=45^{\circ}$. The periods are $d_{x}=d_{y}=15 \mathrm{~mm}$ and the length on the vertical lines is $l=7.5 \mathrm{~mm}$.

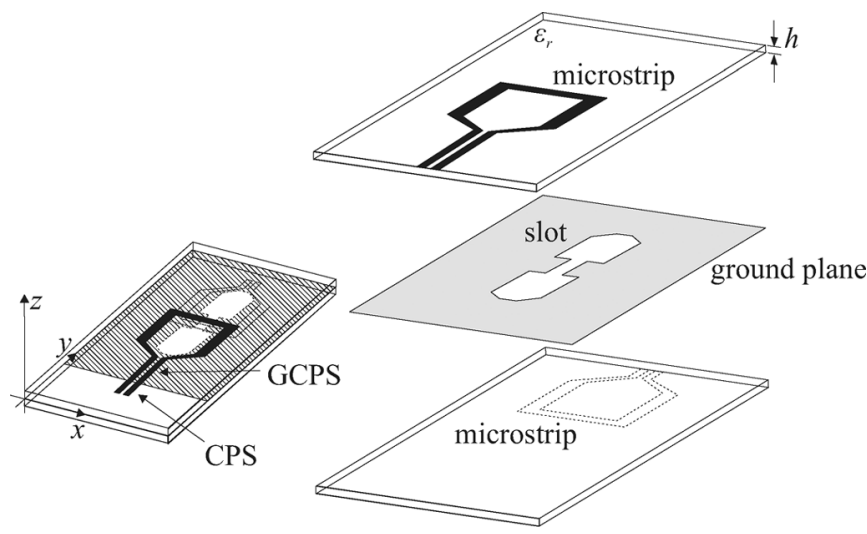

Fig. 5. Layout of the CPS/GCPS transformer. The thickness of two dielectric substrates is $h$ and the permittivity is $\varepsilon_{r}$.

appear at higher frequencies, outside the operational bandwidth of the array. Note that the resonance depicted in Fig. 3 is the one associated with common mode only and typically occurs at the lowest frequency. Other resonances may appear at higher frequencies, which involve combinations of common and differential modes resulting in unbalanced currents.

\section{DESIGN OF PCB TRANSFORMERS}

The path of the common-mode current can be shortened by introducing a series transformer that only allows the passage of differential currents and constitutes an open circuit for the common mode. To realize such a component, one can resort to completely planar slot coupling between microstrip lines as in [17].

\section{A. CPS/GCPS Transformer}

A schematic view of the component is shown in Fig. 5 where the ground plane on which the slot is etched is assumed to be of infinite extent along $x$. The component is divided in two parts separated by the ground plane. The part at $z=h$, here in after the primary circuit, comprises a transition from CPS lines to grounded CPS (GCPS) lines, then a power divider that splits the circuit in two microstrip-like equal halves, which are eventually reconnected in correspondence of a coupling slot. The secondary circuit is the same as the primary, but mirrored with respect to the slot. The initial input from the CPS lines can be associated with a differential-mode or a common-mode type of current. In both cases the equivalent detailed circuits are the same as in Fig. 6. However, from Fig. 6 it is apparent that the common-mode input corresponds to a zero of electric current in correspondence of the 

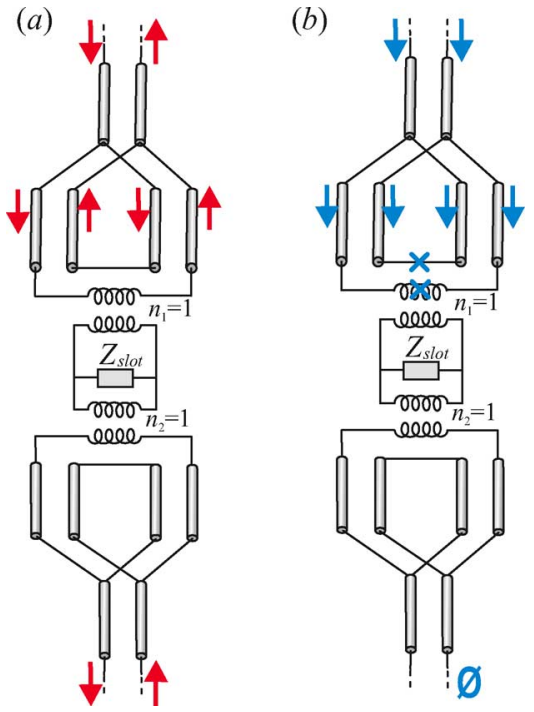

Fig. 6. Equivalent transmission line model of the transition in Fig. 5, for $(a)$ differential input and $(b)$ common input.

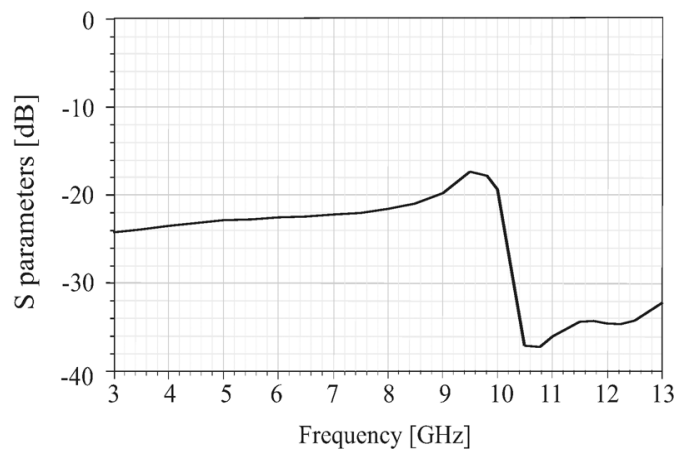

Fig. 7. Common-mode rejection of the CPS/GCPS transition in Fig. 5. The transition is optimized for $100 \mathrm{Ohms} \mathrm{impedance.}$

slot. In turn, this translates in no electric current being excited in the secondary circuit of the transformer (at $z=-h$ ).

The common-mode blocking by these type of components can be highlighted in Fig. 7, where the S12 for the common mode is reported as a function of the frequency. Note that the common mode is rejected to $-17 \mathrm{~dB}$ 's in the worst case over a wideband. While this rejection is intrinsic in this type of transformer, the achievement of unattenuated differential signals depends on the quality of the matching.

Fig. 8 shows the equivalent circuit transformation steps that can be applied to the circuit in Fig. 6(a) in order to obtain an estimate of the input impedance for the array cell and for the differential mode. The maximum power transfer for the differential mode is obtained when the connected array loading $\left(Z_{\text {cell }}\right)$ is matched to the differential-mode line impedance $\left(Z_{0 \text { cell }}\right)$, which is realized by the series of the two microstrip lines, each of impedance $Z_{0 \mathrm{MS}}$. So the condition is $Z_{0 \text { cell }}=2 Z_{0 \mathrm{MS}}=Z_{\text {cell }}$. Let us also focus on the simplifying and realistic situation in which one wants to realize unitary transforming ratios between the primary and secondary circuits and the slot access points, $n_{1} \approx n_{2} \approx 1$. In this case, the load $\left(Z_{\text {cell }}\right)$ is transferred at the slot level $\left(S-S^{\prime}\right)$ and the equivalent impedance at $\left(S-S^{\prime}\right)$ looking upward is $Z_{\|}=Z_{\text {cell }} \| Z_{\text {slot }}$, where $Z_{\text {slot }}$ is the impedance across the slot in the absence of the microstrip lines. When $Z_{\text {cell }} \ll Z_{\text {slot }}$, the presence of the slot is negligible and the differential signal is completely transmitted to the secondary circuit, in fact $n^{2} Z_{\|}=n_{1} n_{2} Z_{\|} \approx Z_{\text {cell }}$.
On the contrary, when the slot loading is comparable to the connected array loading, a significant part of the power received by the connected array is re-radiated by the slot before being transferred to the secondary circuit. This limits the useful bandwidth of the transition. Since the condition for high transmission levels is $Z_{\text {cell }} \ll Z_{\text {slot }}$, a resonant slot with high impedance, together with a smaller value of $Z_{0 \text { cell }}\left(\approx Z_{\text {cell }}\right)$, implies larger useful bandwidths for the transformer. In order to highlight this effect, two transitions using the same slot, whose impedance is shown in Fig. 9(a), are considered. The first transition is optimized for $Z_{0 \text { cell }}=200 \Omega$, while the second is optimized for $Z_{0 \text { cell }}=100 \Omega$. Fig. 9 shows the $S$-parameters associated with these two transitions. The relative bandwidth associated with the lower impedance cell is much larger.

\section{B. CPS/MS Balun}

The design of CPS/GCPS transformers described in the previous section can be easily adapted to CPS/MS balun designs. The primary circuit and the slot remain the same, while in the secondary circuit one branch of the GCPS lines becomes a quarter wavelength open stub, while the other branch constitutes the unbalanced MS input. The geometry of the balun is shown in Fig. 10.

\section{EXAMPles of ARRAY FEEDING CiRCUIT DESIGN}

The transformer described in Section III can be the key component of a periodic cell of a two-dimensional connected array. In order to minimize the number of $\mathrm{T} / \mathrm{R}$ modules, the periods in $x$ and $y$ are maintained at $0.5 \lambda_{0}$ at the highest useful frequency $(10 \mathrm{GHz})$. As examples, let us consider the following two configurations.

1) In each periodic cell of the array there is only one feeding point with the corresponding transformer [see Fig. 11(a)]. In this case, the periods are $d_{x}=d_{y}=\lambda_{0} / 2$ and the impedance of the unit cell is $Z_{\text {cell }}=200 \Omega \approx \zeta_{0} / 2$, where $\zeta_{0}$ is the free space characteristic impedance. Accordingly, a transformer optimized for $Z_{0 \text { cell }}=200 \Omega$ is considered.

2) Each periodic cell is fed at two points, with a separation distance of $\lambda_{0} / 4$ [see Fig. 11(b)]. The impedance at each feed point is $Z_{\text {cell }}=100 \Omega$ and the transformer is also designed for $Z_{0 \text { cell }}=$ $100 \Omega$. A Wilkinson power divider is included to re-establish the same number of $\mathrm{T} / \mathrm{R}$ modules.

The two cases differ for the operational bandwidth of the transformers, as was shown in Fig. 9(b). Therefore, the active reflection coefficients for the case 2 when scanning toward $\theta=45^{\circ}$ and $\phi=45^{\circ}$ exhibits a wider $-10 \mathrm{~dB}$ 's relative bandwidth, as expected [Fig. 12(a)]. However, for the $200 \Omega$ design, even within the frequency band in which a good matching is achieved, high losses are observed in terms of cross-polarization level. Fig. 12(b) shows the X-pol levels for the two considered cases. The difference between the two curves can be associated with the different length $p$ of the dipole and the primary circuit of the transformer (see Fig. 11). In the case 1, the length $p$ becomes longer than one equivalent wavelength at the highest frequency, allowing common-modes resonances to appear inside the bandwidth of the array. Case 2 instead permits having a shorter length $p$, shifting the resonance at frequencies higher than $10 \mathrm{GHz}$. As a consequence, a sensibly lower X-pol ratio is obtained with the second approach.

\section{A. Finite Ground Planes}

Note that the transformer in Section III has been introduced assuming infinite ground planes surrounding the slots. In practice, when used to feed connected arrays, the ground plane will be limited. The effect of this finiteness is not negligible, but was accounted for in the simulations presented in this section. 


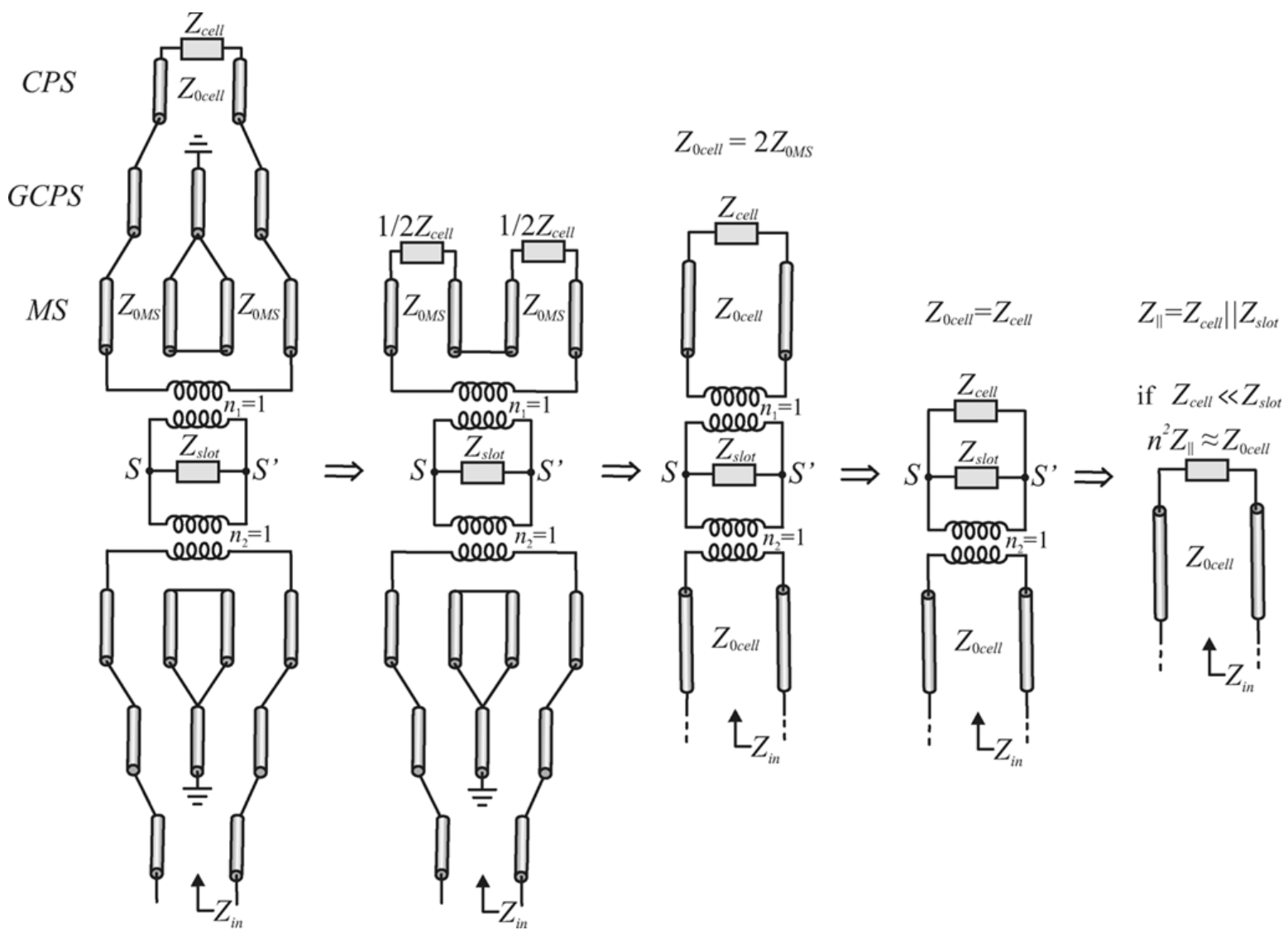

Fig. 8. Equivalent circuit transformation steps for the differential-mode currents.

(a)

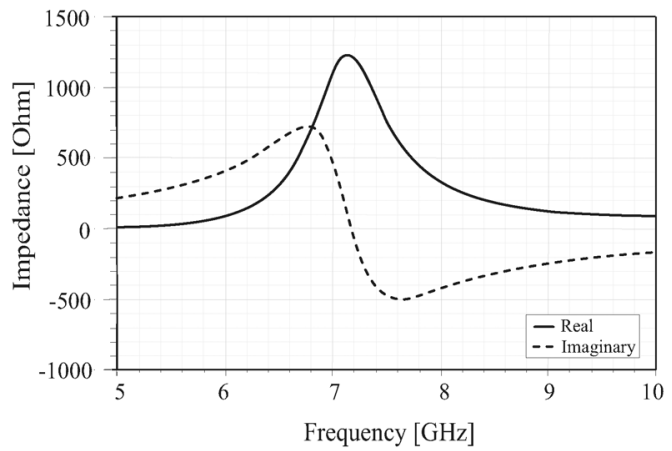

(b)

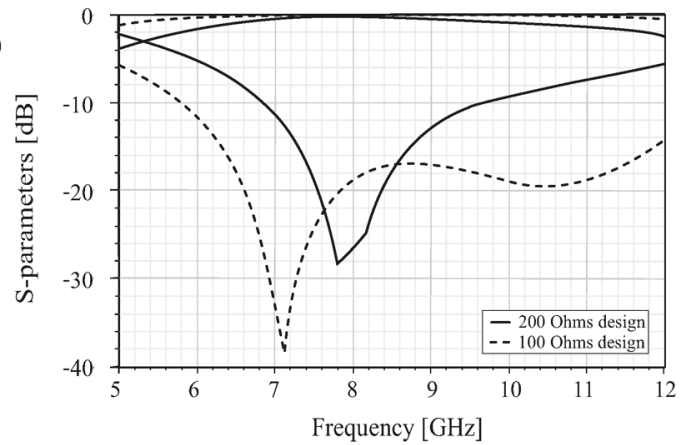

Fig. 9. (a) Input impedance of the slot etched on an infinite ground plane, in the absence of the microstrip circuits. (b) Reflection and transmission coefficient of two transition optimized for $Z_{0 \text { cell }}=200 \Omega$ and $Z_{\text {ocell }}=100 \Omega$, respectively.

\section{CONCLUSION}

A strategy to avoid common-mode resonances in arrays of connected dipoles has been presented. In order to improve the polarization purity,

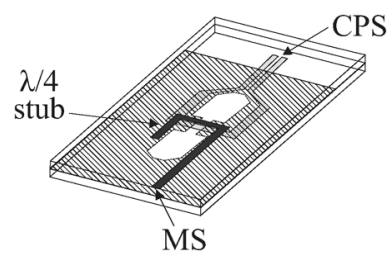

Fig. 10. Layout of the CPS/MS balun transformer.

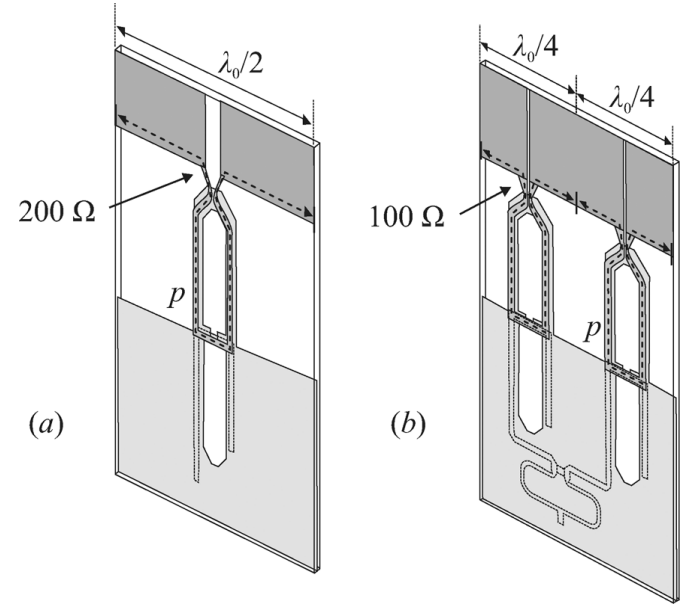

Fig. 11. Geometry of a periodic cell a connected dipole array with $(a)$ single feed per cell and with $(b)$ double feed per cell.

an aperture-coupling-based transformer has been designed, acting as a common-mode rejection circuit. This component is not effective in an array with half wavelength spacing between the elements, because continuous current paths in the order of a wavelength are still undergoing 
(a)

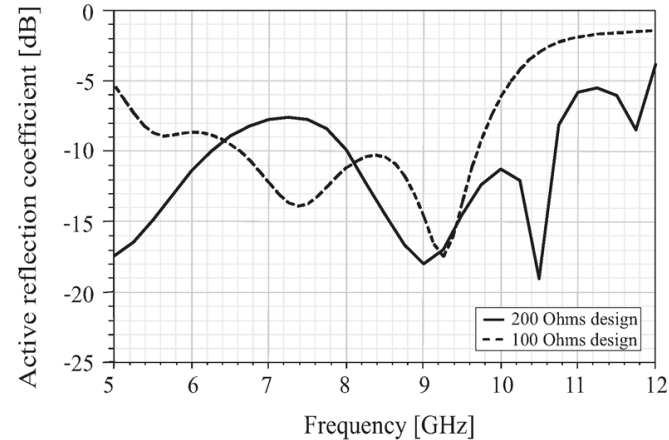

(b)

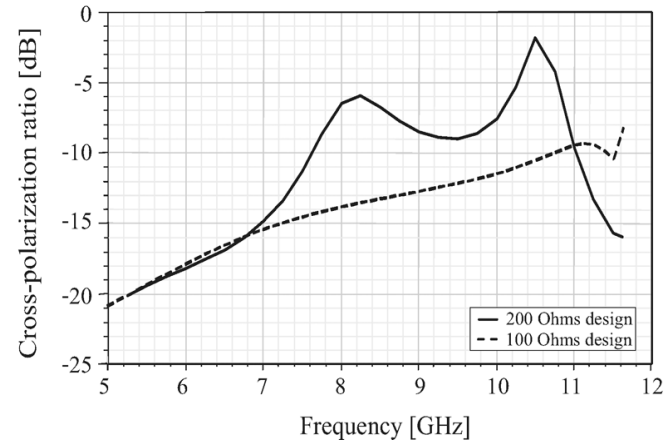

Fig. 12. (a) Active reflection coefficient and (b) X-pol ratio for the two geometries in Fig. 11, when scanning towards $\theta=45^{\circ}$ and $\phi=45^{\circ}$.

common-mode propagation. The proposed solution is splitting the periodic cell in two subcells along the longitudinal direction $(x)$, each comprising a transformer but both connected to the same T/R module. Infinite array simulations highlight the lowering of the cross-polarization levels. Even denser sampling $(\times 4)$ could be possible by using high permittivity dielectrics, which allow reducing the transformer size. This may become necessary if the array is backed by a reflector for increased front to back ratio, and the overall cell impedance becomes $400 \Omega$.

\section{REFERENCES}

[1] M. V. Ivashina, M. N. M. Kehn, P. S. Kildal, and R. Maaskant, "Decoupling efficiency of a wideband Vivaldi focal plane array feeding a reflector antenna," IEEE Trans. Antennas Propag., vol. 57, no. 2, pp. 373-382, Feb. 2009.

[2] S. G. Hay, F. R. Cooray, J. D. O’Sullivan, N.-T. Huang, and R. Mittra, "Numerical and experimental studies of a dual-polarized planar connected-array antenna for the Australian square kilometer array pathfinder," presented at the IEEE Antennas and Propagation Symp., Charleston, SC, Jun. 1-5, 2009

[3] B. Tomasic and N. Herscovici, "Analysis of cylindrical array of infinitely-long slots fed by connected dipoles," presented at the P IEEE Antennas and Propagation Symp., Charleston, SC, June 1-5, 2009.

[4] Core Science Requirements for the European SPICA Instrument, ESIRAL-REQ-0012, Iss. 0.1..

[5] Y. S. Kim and K. S. Yngvesson, "Characterization of tapered slot antennas feeds and feed array," IEEE Trans. Antennas Propag., vol. 38, pp. 1559-1564, Oct. 1990.

[6] M. C. van Beurden et al., "Analysis of wideband infinite phased arrays of printed folded dipoles embedded in metallic boxes," IEEE Trans. Antennas Propag., vol. 48, no. 5, pp. 784-789, May 2000.

[7] M. A. Gonzalez de Aza, J. Zapata, and J. A. Encinar, "Broad-band cavity-backed and capacitively probe-fed microstrip patch arrays," IEEE Trans. Antennas Propag., vol. 50, no. 9, pp. 1266-1273, Sep. 2002.

[8] W. S. T. Rowe, R. B. Waterhouse, and C. T. Huat, "Performance of a scannable linear array of Hi-Lo stacked patches," IEE Proc. Microwave, Antennas Propag., vol. 150, no. 1, pp. 1-4, Feb. 2003.

[9] H. Wheeler, "Simple relations derived from a phased array antenna made of an infinite current sheet," IIEEE Trans. Antennas Propag., vol. 13, pp. 506-514, 1965.
[10] A. Neto and J. J. Lee, "Infinite bandwidth long slot array," IEEE Antennas Wireless Propag. Lett., vol. 4, pp. 75-78, 2005.

[11] A. Neto and J. J. Lee, "Ultrawide-band properties of long slot arrays," IEEE Trans. Antennas Propag., vol. 54, no. 2, pp. 534-543, Feb. 2006.

[12] A. Neto, D. Cavallo, G. Gerini, and G. Toso, "Scanning performances of wide band connected arrays in the presence of a backing reflector," IEEE Trans. Antennas Propag., vol. 57, no. 10, pp. 3092-3102, Oct. 2009

[13] S. G. Hay J and D. O'Sullivan, "Analysis of common-mode effects in a dual-polarized planar connected-array antenna," Radio Sci., vol. 43, Dec. 2008, RS6S04, doi:10.1029/2007RS003798.

[14] E. de Lera Acedo et al., "Study and design of a differentially-fed tapered slot antenna array," IEEE Trans. Antennas Propag., vol. 58, no. 1, pp. 68-78, Jan. 2010.

[15] J. B. Knorr, "Slot-line transitions," IEEE Trans. Microw. Theory Tech. pp. 548-554, May 1974.

[16] A. C. Ludwig, "The definition of cross polarization," IEEE Trans. Antennas Propag., vol. AP-21, pp. 116-119, Jan. 1973.

[17] N. Herscovici and D. M. Pozar, "Full-wave analysis of aperture-coupled microstrip lines," IEEE Trans. Microw. Theory Tech., vol. 39, no. 7, pp. 1108-1114, Jul. 1991.

\section{Reducing Mutual Coupling for an Extremely Closely-Packed Tunable Dual-Element PIFA Array Through a Resonant Slot Antenna Formed In-Between}

Shuai Zhang, Salman Naeem Khan, and Sailing He

\begin{abstract}
An efficient mutual coupling reduction method is introduced for an extremely closely packed tunable dual-element planar inverted-F antenna (PIFA) array. High isolation can be achieved through a $\lambda_{0} / 2$ folded slot antenna formed by a slot on the ground plane and the neighboring edges of the two PIFAs. Direct coupling is blocked by the slot antenna through radiating the coupling power into free space. A measured isolation of more than $36.5 \mathrm{~dB}$ can be achieved between the two parallel individual-element PIFAs operating at 2.4 GHz WLAN band with an inter-PIFA spacing of less than $0.063 \lambda_{0}$ (center to center) or $0.0147 \lambda_{0}$ (edge to edge). Since there is only a narrow slot antenna formed between the PIFAs in the present method, the distance can be further reduced to less than $0.0016 \lambda_{0}$ (edge to edge) with the maximal isolation of better than $40 \mathrm{~dB}$. Both measured and simulation results show the effectiveness of the present mutual coupling reduction method.
\end{abstract}

Index Terms-Diversity antennas, mutual coupling, planar inverted $\mathbf{F}$ antenna (PIFA), slot antenna.

\section{INTRODUCTION}

Muliple-input and multiple-output (MIMO) communication systems have received much attention as a practical method to substantially increase wireless channel capacity without the need for additional power or spectrum in rich scattering environments [1]-[3]. However, several practical requirements exist for achieving the predicted high data rates

Manuscript received July 07, 2009; revised February 02, 2010; accepted February 08, 2010. Date of publication May 18, 2010; date of current version August 05, 2010. The work was supported in part by VINNOVA (Sweden) for "IMT advanced and beyond."

S. Zhang and S. He are with Centre for Optical and Electromagnetic Research, Zhejiang University, Hangzhou 310058, China and also with the Division of Electromagnetic Engineering, School of Electrical Engineering, Royal Institute of Technology, S-100 44 Stockholm, Sweden (e-mail: sailing@ieee.org).

S. N. Khan is with the Department of Physics, COMSATS Institute of Information Technology, Lahore, Pakistan.

Color versions of one or more of the figures in this communication are available online at http://ieeexplore.ieee.org.

Digital Object Identifier 10.1109/TAP.2010.2050432 